\title{
Study on Aesthetic Analysis of Photographic Images Techniques to Produce High Dynamic Range Images
}

\author{
Vikram More \\ Dept. of CS/TT, \\ Symboisis institute of Technology, \\ Pune.
}

\author{
Poorva Agrawal \\ Dept. of CS/IT, \\ Symboisis institute of Technology, \\ Pune.
}

\begin{abstract}
Recent Advancements in image acquisition as well as visual computing leads easy and cheap availability of technology. Additionally, it's more user friendly for average user. Using such new technologies end users expected to be more appealing images. However, producing the appealing images needs also needs the enough knowledge of aesthetic principles during process of acquisition and editing. The average user does not have complete training and experience of doing such tasks. Therefore, it is required to have automatic method in which modelling of aesthetic principles and building systems that can generate aesthetic signature to generate more appealing images. There are number of methods introduced under different categories for automated aesthetic analysis of photographic images with goal of generating more appealing images such as HDR. In this paper, first we are presenting details on Aesthetic Quality Assessment and Attributes, then different aesthetic analysis methods have been studied. The information of different camera technology is discussed in this paper. The comparative study of all reviewed method is presented with accuracy analysis to end this paper
\end{abstract}

\section{Keywords}

Aesthetic Analysis, Image Acquisition, Aesthetic Signature, HDR Image, Image Quality, Photographic Image.

\section{INTRODUCTION}

Now day's visual data handling is growing significantly, and will continue to do so due to the availability of ubiquitous and cheap sensors, sharing platforms and new social trends. Artificial intelligence systems have proven useful for processing and interpreting this preponderance of data. In the last decade, the computer vision and image retrieval community was focused on developing tools for semantic analysis of multimedia content. While this is still a very active research field, new questions are arising. These questions are about visual properties beyond visual semantics, such as image preference, effectiveness, and memorability [1], as well as object importance. Answering subjective, human centric questions such as someone find this image aesthetically pleasing is very challenging, even for humans. However, it was experimentally shown that these visual cognition phenomena can be predicted using data-driven approaches [2]. The objective of image quality assessment is to design methods which can automatically predict the perceived quality of an image. Aesthetic models have many applications of practical value. In image retrieval systems, similar images (from a content-based perspective) could be re-ranked using aesthetic properties. They could help a user to select the best pictures from his collection to make photo albums. Also, these models could be deployed directly in photo cameras to make real-time suggestions. Image quality assessment can be seen as a binary classification problem: is this image "good" or "bad"? It is an intrinsically challenging problem for several reasons. Firstly, visual data is very rich and ambiguous. Secondly, when judging photographs, people are often confronted to personal tastes. Finally, if one might agree that low level degradations (e.g. out of focus image) are - in general - an indicator of poor quality, it is more difficult to find a consensus on higher level visual properties such as color harmonies, layout, lighting conditions, etc. With all these difficulties, one might even question the possibility to learn generic models encoding photographic preference [3] [4].

However, there is some agreement between professionals, about some best photographic practices (e.g. rule of thirds) as well as photographic techniques (e.g. macro). Based on this knowledge, previous work on image quality assessment has proposed hand-crafted visual descriptors, to mimic these photographic rules. Combined with supervised classifiers, they have achieved good results in predicting image quality [5]. Despite the fact that the described hand-crafted features are aesthetically motivated, they have some disadvantages i) they are non-exhaustive: they can never cover all possible photographic principles ii) they are computational expensive, at least for the most successful ones, and iii) they use heuristics, which may not generalize well to similar applications [6].

In this paper, we have to present the literature review study on recent methods for aesthetic image quality analysis using different approaches with their comparative analysis. Additionally, we are presenting the different camera technologies with their configurations. In section II, we are presenting the information of Aesthetic Quality Assessment and Attributes. Section III presenting the literature review of different methods. Section IV, presents the different cameras comparative study. Section V, presents the comparative analysis of recent methods. Finally, conclusion is presented in section VI.

\section{AESTHETIC ATTRIBUTES}

Image quality assessment process is aiming to deliver the computational signature which can be utilized for automatic image quality prediction. Pattern recognition tools, db. and textual image quality tools are some integrated collection of tools used for aesthetic quality assessment. Direct and indirect methods are used to assess the quality of an image. It includes subjective and objective methods. In direct method, subjective method includes psychophysical experiments with the participation of human experts and objective method includes computing suitable image qualities directly from the digital image. In indirect method, objective method includes quantifying the performance of an image-based task done by the domain expert and/or by a computational system, and subjective method include the performance of the imaging /rendering device on suitable set of target image is assessed by using ad-hoc designed software tools one or more direct 
method. For an image with some imperfections quality can be defined by the absence of certain type of distortions like ringing, compression, banding and blur. No reference (NR) type of quality assessment is significantly more challenging because such quality metrics do not utilize a reference image; they only look at the image under test. Full-reference (FR) type of image quality assessment performs a direct comparison between the image under test and the reference image [7].

Golden triangle rule is the composition rule in photography where diagonal lines divide the image corner to corner. This feature can be calculated by creating three diagonal guides by marking the vertical edges of the screen 1/6th of the height from the top and 1/6th from the bottom. Similarly mark the horizontal edges 1/6th of the width from the left and 1/6th from the right. Now connect the upper left horizontal mark with the lower right vertical mark, the upper left vertical mark with the lower right horizontal mark, and the upper left corner with the lower right corner [7]. The picture can be made more pleasing and dynamic by placing natural elements that form a line along these diagonal guides. Exposure of lights can be considered as a good discriminate between high and low quality photos. Too much exposure leads to brighter shots which results in lower quality photos and those that are too dark are often also not interesting [8].

Rule of thirds is the composition rule in photography which dictates how an image should be composed in order to create an aesthetically pleasing result. This rule states that the center of interest in a photograph is situated in one of the four possible intersections of the lines that divide the image into nine rectangles. Photographs that follow this rule have the main object stretch from an intersection up to the center of the image. The rule of thirds is applied by aligning a subject with the guide lines and their intersection points, placing the horizon on the top or bottom line, or allowing linear features in the image to flow from section to section. The main reason for observing the rule of thirds is to discourage placement of the subject at the center, or prevent a horizon from appearing to divide the picture in half [7]. There are three main aesthetic attributes on which image quality is majorly depends such as:

\section{- Generality}

- Relation to photographic rules

- Clear definition

\section{LITERATURE REVIEW}

There are number of methods presented over Aesthetic Analysis of Photographic Images which are categorized in different categories such as Computational aesthetic judgment methods, Image quality assessment methods, Subjective evaluation of visual attributes methods etc. Below we discussed methods under these categories as showing in figure 1.

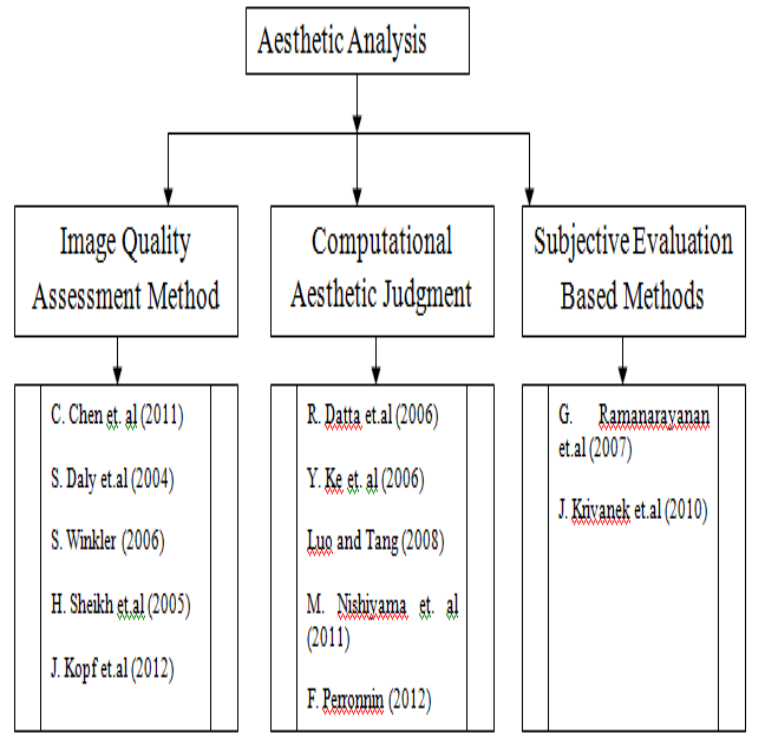

Fig.1. Different Categories of Aesthetic Analysis Methods

\subsection{Image Quality Assessment}

In [6], author introduced a universal, reference-free blurriness measurement approach. While some other methods are designed for a particular source of blurriness such as blockbased compression, the proposed is universal in that it should work for any source of blur. The method of this paper models the gradient image of the given image as Markov chain and utilizes transition probabilities to compute a blurriness measure. This is the first time that transition probabilities are applied to perceptual quality assessment. In this method author first computed the transition probabilities for selected pairs of gradient values and then combine these probabilities, using a pooling strategy, to formulate the blurriness measure.

In [7], presents method for prevention and removal of false contour artifacts from photography images. In applications where it is only possible to affect the image after the bit-depth losses have already occurred, it is impossible to accurately restore the loss of low-amplitude detail. However, it is possible to remove the false contours. Of the several approaches used to remove false contours, we will discuss predictive cancellation and its dependence on the spatial frequency localization and masking properties of the visual system. We discuss the key visual properties that arose while investigating these two applications, which include the optical transfer function (OTF) of the eye, masking by noise, and contour integration.

In [8], author presented the review on perceptual video quality metrics. Author classified the video quality measurement schemes and review existing approaches with a focus on nonintrusive quality metrics, which do not require access to the reference video. In short, evaluated three different noreference blockiness metrics and compare their performance.

In [9], author introduced to use Natural Scene Statistics (NSS) to blindly measure the quality of images compressed by JPEG2000 (or any other wavelet based) image coder. Author claiming that the natural scenes are containing non-linear dependencies that are disturbed by the compression process, and that this disturbance can be quantified and related to human perceptions of quality. This method introduced an implementation of philosophy for images distorted by JPEG2000 (or any other wavelet based) compression. 
JPEG2000 compression disturbs the non-linear dependencies that are present in natural images. Adapting a non-linear statistical model for natural images by incorporating quantization distortion modelling, we presented an algorithm for quantifying the departure of compressed images from expected natural behavior, and calibrated this quantification against human judgements of quality.

In [10], author introduced a data-driven method to predict the quality of an image completion method. Proposed approach in this paper was based on the state-of-the-art non-parametric framework of Wexler et al. [2007]. It uses automatically derived search space constraints for patch source regions, which lead to improved texture synthesis and semantically more plausible results. These constraints also facilitate performance prediction by allowing authors to correlate output quality against features of possible regions used for synthesis. This proposed algorithm was used by author to first crop and then completes stitched panoramas. Their predictive ability is used to find an optimal crop shape before the completion is computed, potentially saving significant amounts of computation. Their optimized crop includes as much of the original panorama as possible while avoiding regions that can be less successfully filled in. Their predictor can also be applied for hole filling in the interior of images.

\subsection{Visual Attributes Subjective Evaluation}

In [11], Author introduced the concept of visual equivalence as a new approach for perceptually based rendering. In a series of psychophysical experiments, it was characterized conditions under which two classes of transformations on illumination maps (blurring and warping) yield images that are visually equivalent to reference solutions. On the basis of these experiments, author derived metrics for predicting visual equivalence for these transformations and in a follow-up experiment and validated that the predictive power of the metrics generalizes across different geometries, materials, and illumination maps. Author is showing that how these metrics can be applied to two existing rendering algorithms in order to increase efficiency while maintaining image fidelity.

In [12], author systematically studies the perceptual effects of VPL based global illumination algorithms on image quality and material appearance. In a series of psychophysical experiments, we study how VPL counts and clamping levels affect visual equivalence, and show how equivalence is modulated by object geometry and material properties. Author validated their findings on shapes, materials, and illumination that were not in our main study. Additionally, proposed simple heuristics to guide rendering, and presented a method for correcting energy losses in VPL renderings to increase equivalence. By explicitly and systematically studying the impact of rendering approximations on appearance this paper takes some initial steps towards providing a strong perceptual foundation for VPL methods, a popular and efficient class of global illumination rendering algorithms. The paper also draws attention to the limitations of VPL methods in their ability to correctly simulate lighting conditions with limited resources.

\subsection{Computational Aesthetic Judgment Methods}

In [1], author established significant correlation between various visual properties of photographic images and their aesthetics ratings. Author shown, through using a communitybased database and ratings, that certain visual properties tend to yield better discrimination of aesthetic quality than some others. Despite the inherent noise in data, SVM-based classifier is robust enough to produce good accuracy using only 15 visual features in separating high and low rated photographs as showing in practical results. In the process of designing the classifier, it was developed a number of new features relevant to photographic quality, including a low depth-of-field indicator, a colorfulness measure, a shape convexity score and a familiarity measure. Even though certain extracted features did not show a significant correlation with aesthetics, they may have applications in other photographic image analysis work as they are sound formulations of basic principles in photographic art.

In [2], author Ke et al. proposed using image features based on common-sense photography and utilize a na"1ve Bayes classifier based on their observation that the interactions between the aesthetic attributes are not linear. The two-fold classification accuracy of all these methods on subjective data is in the $70 \%$ range.

In [3], author reported a significant improvement in accuracy by extracting a rectangular image window that contains most of the high frequency details, and formulating features that take into account this two-fold segmentation. Authors first extract the subject region from a photo, and then formulate a number of high level semantic features based on professional photography techniques to classify high quality and low quality photos. In this article authors also conducted the first video quality evaluation study based on professional video making techniques.

In [4], author tackles the challenging problem of evaluating the color harmony of photos with a particular focus on aesthetic quality classification. A key point is that a photograph can be seen as a collection of local regions with color variations that are relatively simple. Author introduced the method for assessing the aesthetic quality of a photo based on the photo's color harmony, called as 'bags-of-colorpatterns.'

In [5], author introduced novel large-scale database for image aesthetics and shown how it can be used to advance research in the field using three sample applications. Author proposed the AVA method through which they explored the factors that make aesthetic analysis such a challenging and intriguing research problem. The experiments shown that not only does the scale of training data matter for increasing performances, but also the aesthetic quality of the images used for training.

There are some more methods introduced in 2012 to 2014 which are studied in next section comparatively.

\section{LETURATURE REVIEW}

Below table 1 is showing the comparative study of some of the aesthetic quality assessment methods.

Table 1: Review and Analysis of Aesthetic Methods

\begin{tabular}{|c|c|c|c|c|}
\hline $\begin{array}{c}\text { Publi } \\
\text { catio } \\
\text { n } \\
\text { Year }\end{array}$ & Authors & $\begin{array}{l}\text { Methodolo } \\
\text { gy }\end{array}$ & $\begin{array}{l}\text { Pros/Co } \\
\text { ns }\end{array}$ & $\begin{array}{l}\text { Accu } \\
\text { racy }\end{array}$ \\
\hline 2011 & $\begin{array}{l}\text { Luca } \\
\text { Marches } \\
\text { otti, } \\
\text { Florent } \\
\text { Perronni } \\
\text { n, } \\
\text { DianeLar } \\
\text { lus, } \\
\text { Gabriela }\end{array}$ & $\begin{array}{l}\text { Generic } \\
\text { Image } \\
\text { Descriptor }\end{array}$ & $\begin{array}{l}\text { i) } \\
\text { Acceptab } \\
\text { le } \\
\text { computat } \\
\text { ion time } \\
\text { for real- } \\
\text { time } \\
\text { applicati } \\
\text { ons. }\end{array}$ & $86 \%$ \\
\hline
\end{tabular}




\begin{tabular}{|c|c|c|c|c|}
\hline & $\begin{array}{l}\text { Csurka } \\
{[17]}\end{array}$ & & $\begin{array}{l}\text { ii) } \\
\text { Classific } \\
\text { ation } \\
\text { rates are } \\
\text { better. } \\
\text { iii) Blur } \\
\text { informati } \\
\text { on can } \\
\text { also be } \\
\text { added to } \\
\text { the color } \\
\text { descripto } \\
\text { rs }\end{array}$ & \\
\hline 2011 & $\begin{array}{l}\text { Hsiao } \\
\text { Hang, } \\
\text { Su, Tse- } \\
\text { wei, } \\
\text { chieh- } \\
\text { chikao, } \\
\text { Winston } \\
\text { Hsu, } \\
\text { shao- } \\
\text { YiChien } \\
\text { [18] }\end{array}$ & $\begin{array}{l}\text { Bottom up } \\
\text { aesthetic } \\
\text { modeling } \\
\text { method }\end{array}$ & $\begin{array}{l}\text { i) } \\
\text { multiple } \\
\text { scores } \\
\text { can be } \\
\text { given } \\
\text { ii) } \\
\text { computat } \\
\text { ion } \\
\text { process } \\
\text { is highly } \\
\text { efficient } \\
\text { iii) } \\
\text { contrast } \\
\text { informati } \\
\text { on is } \\
\text { consider } \\
\text { ed }\end{array}$ & $\begin{array}{l}92.06 \\
\%\end{array}$ \\
\hline 2012 & $\begin{array}{l}\text { Anish } \\
\text { Mittal, } \\
\text { Rajiv } \\
\text { Soundara } \\
\text { rajan and } \\
\text { Alan C } \\
\text { Bovik } \\
{[16]}\end{array}$ & $\begin{array}{l}\text { Natural } \\
\text { Image } \\
\text { Quality } \\
\text { Evaluator } \\
\text { (NIQE) }\end{array}$ & $\begin{array}{l}\text { NIQE } \\
\text { performs } \\
\text { better } \\
\text { than the } \\
\text { FR } \\
\text { PSNR } \\
\text { and } \\
\text { SSIM }\end{array}$ & $\begin{array}{l}91.47 \\
\%\end{array}$ \\
\hline 2013 & $\begin{array}{l}\text { Tsung- } \\
\text { Jung } \\
\text { Weisi } \\
\text { Lin, C.C. } \\
\text { Jay Kuo } \\
\text { [15] }\end{array}$ & MMF & $\begin{array}{l}\text { i) highly } \\
\text { flexible } \\
\text { ii)excelle } \\
\text { nt } \\
\text { performa } \\
\text { nce }\end{array}$ & $\begin{array}{l}91.07 \\
\%\end{array}$ \\
\hline 2013 & $\begin{array}{l}\text { Congcon } \\
\mathrm{g} \\
\mathrm{Li} \text {, } \\
\text { Tsuhan } \\
\text { Chen } \\
{[14]}\end{array}$ & $\begin{array}{l}\text { Data Driver } \\
\text { Machine } \\
\text { Learning } \\
\text { Problem }\end{array}$ & $\begin{array}{l}\text { Regressi } \\
\text { on } \\
\text { approach } \\
\text { is used to } \\
\text { estimate } \\
\text { the } \\
\text { quality } \\
\text { score }\end{array}$ & $87 \%$ \\
\hline 2014 & $\begin{array}{l}\text { Xin Lu, } \\
\text { Zhe Lin, } \\
\text { Jian chao } \\
\text { Yang, } \\
\text { James Z } \\
\text { [13] }\end{array}$ & Rapid & $\begin{array}{l}\text { i) It takes } \\
\text { more } \\
\text { computat } \\
\text { ion time. } \\
\text { ii) Local } \\
\text { and } \\
\text { global } \\
\text { features } \\
\text { of an } \\
\text { image } \\
\text { are taken } \\
\text { into } \\
\text { account. }\end{array}$ & $\begin{array}{l}71.2 \\
\%\end{array}$ \\
\hline
\end{tabular}

\section{CAMERA PROPERTIES}

Table 2 is showing the comparative analysis different camera technologies used for photography.

Table 2:Comparative Study of Cameras

\begin{tabular}{|c|c|c|c|}
\hline $\begin{array}{l}\text { Propert } \\
\text { ies }\end{array}$ & Sony & LG & Samsung \\
\hline $\begin{array}{l}\text { Display } \\
\text { technol } \\
\text { ogy }\end{array}$ & $\begin{array}{l}\text { TRILU } \\
\text { MINOS } \\
\text { (IPS) }\end{array}$ & IPS & AMOLED \\
\hline $\begin{array}{l}\text { Display } \\
\text { type }\end{array}$ & $\begin{array}{l}\text { LED \& } \\
\text { LCD \& } \\
\text { CLEDIS }\end{array}$ & $\begin{array}{l}\text { OLED } \\
\& \\
\text { LED } \\
\& \\
\text { LCD } \\
\end{array}$ & $\begin{array}{ll}\text { AMOLED } & \& \\
\text { SUPER } & \\
\text { AMOLED } & \& \\
\text { OLED } & \end{array}$ \\
\hline $\begin{array}{l}\text { Support } \\
\text { resoluti } \\
\text { on }\end{array}$ & $\begin{array}{l}\text { FULL } \\
\text { HD, 4K, } \\
4 \mathrm{~K} \\
\text { (HDR) } \\
8 \mathrm{~K}, \quad 8 \mathrm{~K} \\
\text { (HDR) }\end{array}$ & $\begin{array}{l}\text { FULL } \\
\text { HD, } \\
4 \mathrm{~K}, \\
5 \mathrm{~K}\end{array}$ & $\begin{array}{l}\text { FULL HD, 4K, } \\
4 \mathrm{~K} \text { (HDR), 8K }\end{array}$ \\
\hline $\begin{array}{l}\text { Display } \\
\text { frequen } \\
\text { cy } \\
\text { /Refresh } \\
\text { rate } \\
\text { support }\end{array}$ & $\begin{array}{l}\text { UP TO } \\
400 \\
\text { AND } \\
800 \mathrm{HZ}\end{array}$ & $\begin{array}{l}\text { UP } \\
\text { TO } \\
200 \\
\text { HZ } \\
\text { TO } \\
400 \\
\text { HZ }\end{array}$ & $\begin{array}{l}\text { UP TO } 240 \mathrm{HZ} \\
800 \mathrm{HZ}\end{array}$ \\
\hline $\begin{array}{l}\text { Display } \\
\text { process } \\
\text { or }\end{array}$ & $\begin{array}{l}\text { BRAVI } \\
\text { A } \\
\text { engine, } \\
\text { X-reality } \\
\text { engine, } \\
\text { X-reality } \\
\text { pro } \\
\text { engine. }\end{array}$ & $\begin{array}{l}\text { UCI - } \\
\text { ENGI } \\
\text { NE }\end{array}$ & $\begin{array}{l}\text { QUAD CORE } \\
\text { PROCESSOR }\end{array}$ \\
\hline $\begin{array}{l}\text { Displa } \\
\text { y } \\
\text { device } \\
\text { s } \\
\text { availab } \\
\text { le }\end{array}$ & $\begin{array}{l}\text { MOBIL } \\
\text { E, TV, } \\
\text { MONIT } \\
\text { OR. }\end{array}$ & $\begin{array}{l}\text { MOBI } \\
\text { LE, } \\
\text { TV, } \\
\text { MONI } \\
\text { TOR. }\end{array}$ & $\begin{array}{l}\text { MOBILE, TV, } \\
\text { MONITOR, } \\
\text { FLEXIBLE } \\
\text { DISPLAY. }\end{array}$ \\
\hline $\begin{array}{l}\text { Display } \\
\text { technol } \\
\text { ogy }\end{array}$ & $\begin{array}{l}\text { TRILU } \\
\text { MINOS } \\
\text { (IPS) }\end{array}$ & IPS & AMOLED \\
\hline
\end{tabular}

\section{CONCLUSION AND FUTURE WORK}

The goal of this paper is to present survey on different aesthetic image quality analysis methods for predicting and generating the quality improvement signature to get HDR images. We have present study on different aesthetic rules and attributes. We have present study on recent techniques for aesthetic image analysis under various categories. The comparative study of most recent methods in terms of pros, cons and accuracy parameters is discussed in this paper. At 
last the important part of HDR imaging different types of cameras has been compared according to their configuration properties.

\section{REFERENCES}

[1] R. Datta, D. Joshi, J. Li, and J. Z. Wang, "Studying aesthetics in photographic images using a computational approach," in Proc. of ECCV, 2006, pp. 7-13.

[2] Y. Ke, X. Tang, and F. Jing, "The design of high-level features for photo quality assessment." in in Proc. of IEEE Conf. on Computer Vision and Pattern Recognition (CVPR), 2006, pp. 419-426.

[3] Y. Luo and X. Tang, "Photo and video quality evaluation: Focusing on the subject," in Proceedings of the 10th European Conference on Computer Vision (ECCV), 2008, pp. 386-399.

[4] M. Nishiyama, T. Okabe, I. Sato, and Y. Sato, "Aesthetic quality classification of photographs based on color harmony," in Proc. of CVPR, 2011, pp. 33-40.

[5] F. Perronnin, "Ava: A large-scale database for aesthetic visual analysis," in IEEE CVPR, 2012, pp. 2408-2415.

[6] C. Chen, W. Chen, and J. A. Bloom, "A universal reference-free blurriness measure," in SPIE vol. 7867, 2011.

[7] S. Daly and X. Feng, "Decontouring: Prevention and removal of false contour artifacts," in Proc. of Human Vision and Electronic Imaging IX, ser. SPIE, vol. 5292, 2004, pp. 130-149.

[8] S. Winkler, "Perceptual video quality metrics - a review," in Digital Video Image Quality and Perceptual Coding, H. R. Wu and K. R. Rao, Eds. CRC Press 2006, 2006, pp. 155-179.

[9] H. Sheikh, A. Bovik, and L. Cormack, "No-reference quality assessment using natural scene statistics: JPEG2000," IEEE Trans. on Image Processing, vol. 14, no. 11 , pp. $1918-1927,2005$.
[10] J. Kopf, W. Kienzle, S. Drucker, and S. B. Kang, "Quality prediction for image completion," ACM Trans. on Graphics (Proc. of SIGGRAPH), vol. 31, no. 6, pp. $131: 1-131: 8,2012$

[11] G. Ramanarayanan, J. Ferwerda, B. Walter, and K. Bala, "Visual equivalence: towards a new standard for image fidelity," ACM Transactions on Graphics (Proc. of SIGGRAPH), vol. 26, 2007.

[12] J. K`riv'anek, J. A. Ferwerda, and K. Bala, "Effects of global illumination approximations on material appearance," ACM Trans. on Graphics (Proc. of SIGGRAPH), vol. 29, pp. 112:1-10, 2010.

[13] Xin Lu, Zhe Lin, Jian chaoYang, James Z wang," RAPID: RAting PIctorial aesthetic using Deep learning", ACM 2014

[14] Christel Chamaret and Fabrice Urban, "No Reference Harmony-guided Quality Assessment", IEEE Conference on Computer Vision and Pattern Recognition Workshops 2013.

[15] Tsung-Jung Liu, Weisi Lin, C.-C. Jay Kuo," image quality assessment using multi method fusion ", IEEE Transactions on Image processing, VOL.22, No.5, May 2013

[16] Anish Mittal, Rajiv Soundararajan and Alan C Bovik, "Making a completely blind image quality analyzer ", IEEE 2012.

[17] Luca Marchesotti, Florent Perronnin, Diane Larlus, Gabriela Csurka, "Assessing the aesthetic quality of photographs using generic image descriptors", IEEE international conference on computer vision 2011.

[18] Hsiao-Hang, Su, Tse-wei chen, Chieh-chi kao, Winston $\mathrm{H} \mathrm{Hsu,} \mathrm{Shao-Yi} \mathrm{Chien,} \mathrm{"Scenic} \mathrm{photo} \mathrm{quality} \mathrm{assessment}$ with bag of aesthetic -preserving features", ACM 2011. 